\title{
Dinâmica Espaço-temporal de Focos de Calor em Duas Terras Indígenas do Estado de Mato Grosso: uma Abordagem Geoespacial sobre a Dinâmica do Uso do Fogo por Xavantes e Bororos
}

\author{
Fabio de Almeida Abreu ${ }^{1}$, Josiane do Socorro Aguiar Souza ${ }^{2}$ \\ ${ }^{1}$ Departamento de Zoneamento Territorial, Ministério do Meio Ambiente, Brasília/DF, Brasil \\ ${ }^{2}$ Faculdade de Tecnologia, Universidade de Brasilia - UnB, Gama/DF, Brasil
}

\begin{abstract}
RESUMO
O objetivo deste artigo foi, com suporte de geotecnologias, estudar a distribuição espaço-temporal dos focos de calor detectados pelos sensores a bordo dos satélites NOAA-12 e NOAA-15 entre os anos de 2005 e 2010, em uma região do leste de Mato Grosso. Observou-se que nas terras indígenas Merure, pertencentes à etnia Bororo, e São Marcos, pertencentes à etnia Xavante, os focos de calor apresentaram padrões distintos, o que pode ser atribuído a diferentes formas de utilização do fogo por essas etnias. Comparando-se os focos nas três áreas, Bororo, Xavante e entorno, notou-se que na terra indígena dos Bororos, existe maior concentração e densidade de focos de calor próximo às rodovias existentes em seu interior. Para a terra indígena dos Xavantes, apesar da existência de uma rodovia em seu interior, os focos de calor se distribuem de forma dispersa por todo o território. A prática da caça com a utilização do fogo pelos Xavantes exerce forte influência nessa distribuição de focos.
\end{abstract}

Palavras-chave: manejo do fogo, densidade Kernel, incêndio, queimadas.

\section{Spatiotemporal Dynamic Analysis of Heat Spots in Two Indigenous Lands of Mato Grosso State: a Geoespatial Approach Over the a Dynamic of Fire Use by Xavantes and Bororos}

\begin{abstract}
The article aimed to use geotechnology to study the occurrence of heat spots detected sensors on board of NOAA-12 and NOAA-15 satellites, between the years 2000 and 2010 in a region located on east of Mato Grosso state. It was observed that in the Merure, belonging to Bororo people and São Marcos, belonging to Xavante people indigenous lands the heat spots were presented in different patterns that can be attributed to the distinct ways of fire management by each ethnic group. The practice of hunting with the use of fire influenced the higher concentration and considerable densities of hot spots distributed throughout inside the Xavante's territory compared to the Bororo's and in the surrounding buffer areas of São Marcos. In the Bororo territory was observed that the hot spots were presented in higher densities close to the highways that crosses its territory.
\end{abstract}

Keywords: fire management, Kernel density, fire, burning. 


\section{INTRODUÇÃO}

No Brasil, os incêndios florestais e as queimadas são problemas antigos, relacionados, principalmente, à cultura do uso do fogo como ferramenta no modelo de cultura desenvolvido pela colonização (Gonçalves, 2005). Para algumas populações indígenas que ocupam originalmente a região leste do Estado de Mato Grosso, o manejo do fogo faz parte da cultura, utilizado como ferramenta tradicional para limpeza de áreas e para a prática da caça (Mistry \& Bizerril, 2011).

Segundo o relatório de monitoramento de Focos de Calor elaborado pela Secretaria Estadual de Meio Ambiente de Mato Grosso (Mato Grosso, 2010), nos anos de 2008 e 2009, a região leste do estado apresentou alta densidade de focos de calor, especificamente nos municípios de Barra do Garças e General Carneiro. Essas áreas críticas incidem sobre a região onde se localizam as terras indígenas São Marcos e Merure.

Os incêndios são causados por processos antrópicas e naturais. As ações antrópicas iniciam-se pelo uso do fogo como ferramenta para atingir as mais variadas finalidades como, por exemplo, expansão das fronteiras de ocupação, conversão da floresta em lavouras e pastagens, controle de pragas e limpeza de terreno (Cunha et al., 2007). As naturais são causadas, frequentemente, por raios (Medeiros \& Fiedler, 2004).

A vasta região do vale do Araguaia mato-grossense foi historicamente ocupada por indígenas da etnia Xavante, que ao longo do tempo perderam seus territórios para os colonizadores e hoje vivem em terras indígenas dispersas na região. O manejo do fogo faz parte da cultura Xavante, utilizado na limpeza de roças e principalmente para a realização de caça em grupo (Welch et al., 2013).

Para não indígenas, a utilização do fogo na prática da caça por indígenas no cerrado é vista de forma preconceituosa. Posey (1987) afirma que o fogo é usado pelos indígenas, porém não para destruir áreas florestadas, nem para ampliar os campos e savanas, mas para manejar as "ilhas de recursos", os chamados apêtês, de vegetação mais densa e rica.

Em relação aos Xavantes, os Bororos tiveram sua cultura alterada de forma mais intensa pelos não indígenas de cultura ocidental. Dentre elas destaca-se a alteração no sistema de cultivo das roças, no qual atualmente não há mais o pousio e a mesma área é usada por períodos mais longos, com auxílio de maquinários. A limpeza da área era feita manualmente com o auxílio do fogo e as roças não eram destocadas. Porém com a introdução das máquinas, na década de 1970, a limpeza passou a ser feita mecanicamente (Pinto \& Garavello, 2002). As práticas agrícolas são semelhantes às práticas adotadas pelos "brancos", seguindo os modelos tradicionais não indígenas.

Atualmente percebe-se a existência de poucas informações disponíveis na literatura que apresentem correlação da contribuição do uso do fogo, por meio de focos de calor detectados por satélites, por essas comunidades tradicionais com a quantidade de focos totais na região e no entorno dessas terras indígenas.

O manejo do fogo faz parte da ecologia do cerrado, a ocorrência de incêndios ocasionais, aos quais tanto a vegetação quanto a fauna estão adaptadas e dos quais, de certa forma, são dependentes. Os povos da etnia Jê têm por prática a realização de queimadas para caçar, fazer a roça, abrir clareiras, entre outras. Manejando o tempo de queima ou preservação das distintas feições do cerrado, moldam o ambiente em suas diversas feições e, assim, produzem o citado espaço híbrido entre sociedade e natureza (Coelho, 2009).

Para os Xavantes, a periodicidade de queima varia em conformidade com as características de cada fitofisionomia. Áreas com campos de murundus também denominadas "apê", crescem mais rápido e podem ser queimadas anualmente. Contudo, essa prática é realizada somente nos meses de junho e julho, quando os ventos ainda não são fortes (Melo, 2007). Já as áreas de cerrado stricto sensu podem ser queimadas a partir de agosto.

O objetivo geral deste estudo foi analisar a distribuição espaço-temporal dos focos de calor nas terras indígenas São Marcos, Merure e municípios limítrofes, Estado do Mato Grosso, com auxílio de geotecnologias.

\section{MATERIAL E MÉTODOS}

\section{1. Área de estudo}

Este trabalho teve como área de estudo a região leste do Estado de Mato Grosso, Região Centro-Oeste do Brasil (Figura 1). A seleção da área de estudo levou em consideração o relatório da SEMA-MT, que identificou no leste de Mato Grosso, regiões com densidade considerável de focos de calor sobrepostos às terras indígenas são Marcos e Merure (Figura 1). 


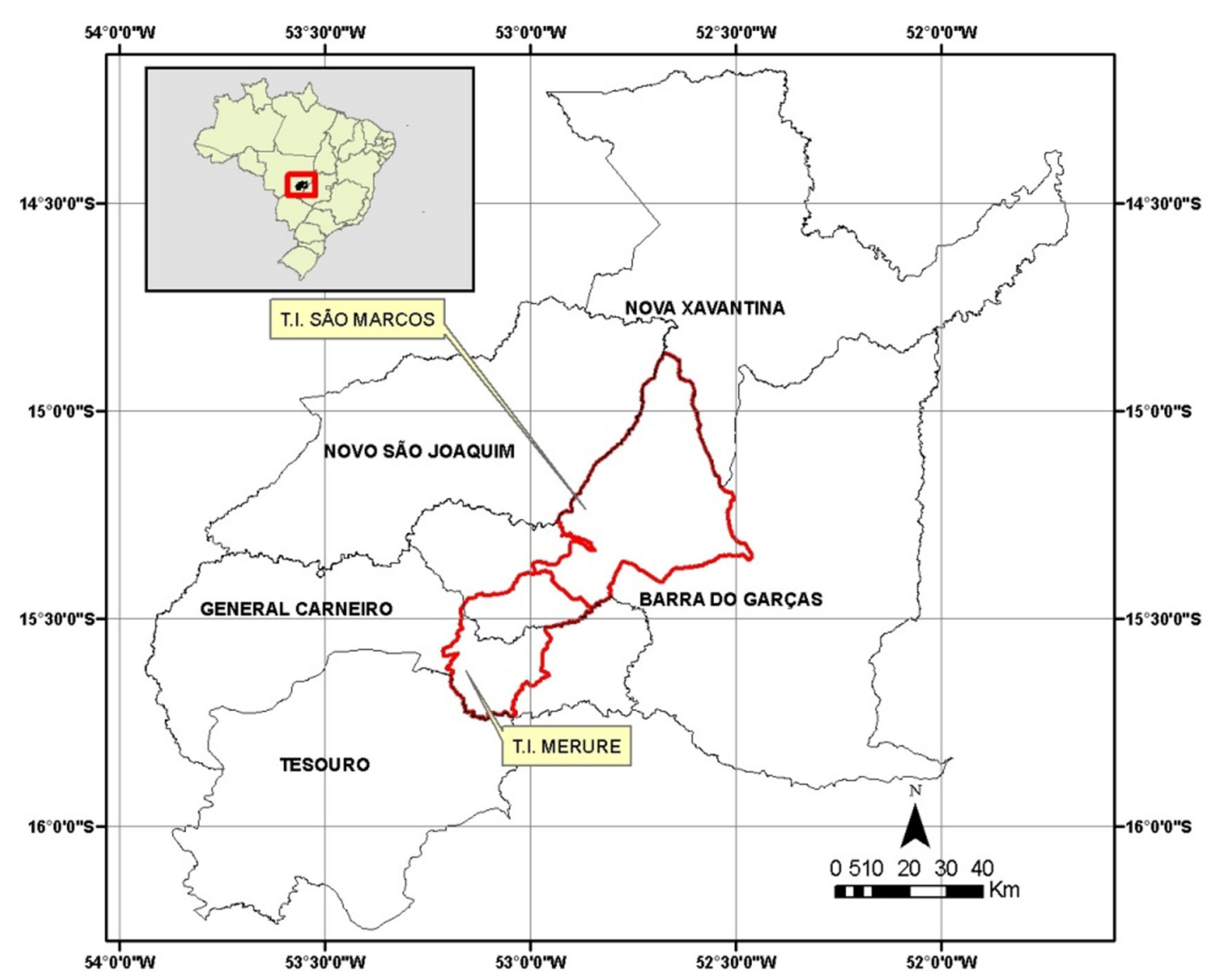

Figura 1. Localização da área de estudo.

Figure 1. Localization of the area of study.

As terras indígenas São Marcos e Merure ocupam 23,5\% do território do município de Barra do Garças e $13 \%$ do município de General Carneiro, ambos localizados na região leste de Mato Grosso. A Terra Indígena Merure tem 82.301,14 ha, que abrangem partes dos territórios dos municípios de Barra do Garças e General Carneiro, nas coordenadas geográficas do centroide da área de $53^{\circ} 04^{\prime} 02^{\prime \prime} \mathrm{W}$ e $15^{\circ} 33^{\prime} 32^{\prime \prime} \mathrm{S}$. Possui população de 524 pessoas da etnia Bororo (FUNAI, 2011). A Terra Indígena São Marcos tem 178.118,30 ha e se localiza no município de Barra do Garças, com coordenadas geográficas do centroide da área de $52^{\circ} 42^{\prime} 50^{\prime \prime}$ W e $15^{\circ} 12^{\prime} 10^{\prime \prime}$ S. Possui população de 1.813 pessoas da etnia Xavante (FUNAI, 2011).

$\mathrm{Na}$ análise sobre as influências dos focos de calor sobre as terras indígenas foram utilizados no estudo as séries dos focos de calor de todos os municípios que fazem divisa com essas terras indígenas: General Carneiro, Barra do Garças, Tesouro, Novo São Joaquim e Nova Xavantina (Figura 1).
Baseado na classificação de Köppen, o clima da região é do tipo Aw, clima quente e úmido, com duas estações definidas (verão chuvoso e inverno seco). A precipitação média anual é de $1.600 \mathrm{~mm}$, temperatura do ar média de $22{ }^{\circ} \mathrm{C}$ e altitude média de $342 \mathrm{~m}$. A umidade relativa, em torno de $70 \%$, sendo que na estação seca pode alcançar 30\% (Albues \& Rosa, 2006).

A vegetação da região é tipicamente de cerrado, caracterizada por apresentar predominantemente estrutura composta por árvores baixas e tortuosas, isoladas ou agrupadas, sobre contínua superfície de gramíneas (Castro \& Kauffman, 1998).

\subsection{Aquisição, seleção e organização dos dados}

O presente trabalho utilizou como insumos os dados geoespaciais disponibilizados de forma gratuita por meio da rede mundial de computadores em sítios eletrônicos de instituições governamentais, que disponibilizam 
informações geoespaciais relacionadas diretamente com o recorte territorial de interesse para este estudo. Para o presente estudo foi adotado o Sistema de Coordenadas Geográficas e Datum South American 1969. Todos os arquivos utilizados foram no formato shapefile. Os focos de calor foram obtidos no Instituto Nacional de Pesquisas Espaciais - INPE, a malha municipal, no Instituto Brasileiro de Geografia e Estatística - IBGE, os limites das terras indígenas, da Fundação Nacional do Índio, as áreas desmatadas e de remanescentes de vegetação, do Instituto Brasileiro do Meio Ambiente e dos Recursos Naturais Renováveis - IBAMA, a malha rodoviária, do Ministério dos Transportes - MT e os limites das unidades de conservação, do Ministério do Meio Ambiente - MMA

O software utilizado foi o ArcGis 9.2 ${ }^{\circledR}$ e a extensão Spatial Analyst e Xtools.

Os dados de focos de calor foram obtidos do processamento diário das imagens termais do sensor AVHRR, a bordo dos satélites NOAA-12 e NOAA-15, no período entre 2005 e 2010 (INPE, 2011), com geometria de pontos, e disponibilizados em períodos máximo de um ano.

Para os satélites NOAA, a $800 \mathrm{~km}$ de distância (órbita polar), trabalhos de validação de campo indicam que uma frente de fogo com cerca de $30 \mathrm{~m}$ de extensão por $1 \mathrm{~m}$ de largura, ou maior, é detectada. Um material em chamas emite energia principalmente na faixa termal média de 3,7 um a 4,1 um do espectro óptico. Utilizam-se as imagens que tenham essa faixa característica e nelas selecionam-se os píxeis (elementos de resolução) com maior temperatura, em geral saturando o sensor (INPE, 2011).

Entretanto, segundo o INPE (2011), há alguns fatores que limitam a detecção, como as frentes de fogo com menos de $30 \mathrm{~m}$, fogo apenas no chão de uma floresta densa, sem afetar a copa das árvores, ocorrência de nuvens cobrindo a região, queimada de pequena duração, fogo em uma encosta de montanha e imprecisão na localização do foco de queima, que no melhor caso é de cerca de $1 \mathrm{~km}$, mas pode chegar a $6 \mathrm{~km}$ (INPE, 2011).

Ambos são considerados satélites de referência para realização de análises temporais pelo INPE para o período de estudo. A seleção desses dois satélites deve-se ao término da operação do NOAA-12, em agosto de 2007, e sua substituição pelo NOAA-15. O satélite NOAA-15 teve seu funcionamento interrompido em dezembro de 2010, devido a problemas técnicos (INPE, 2011). Considerando, dessa forma, que a média de focos de calor para a região de estudo é relativamente baixa nesse mês, o valor do mês de dezembro de 2010 foi desconsiderado.

Os dados geoespaciais de focos de calor foram organizados por ano e em uma única base de dados, com a finalidade de facilitar a visualização das informações acumuladas e manipulação e edição de sua tabela de atributos. Outros dados vetoriais foram organizados da mesma forma.

\subsection{Tratamento, interpretação e geração de dados}

Após a compilação dos dados vetoriais adquiridos, eles foram sobrepostos à área de estudo, para iniciar o processo de interpretação das informações e geração de dados derivados.

Após a sobreposição dos dados dos focos de calor e limites territoriais, dados matriciais de densidade de focos de calor acumulado para o período de estudo foram gerados por meio do algoritmo estimador de densidade de Kernel. As densidades foram classificadas em nove classes: não relevante, baixa, média baixa, média, média alta, alta, muito alta, extremamente alta e crítica, seguindo o modelo de legenda aplicada pela SEMA/MT em seu relatório de monitoramento de focos de calor de 2008 e 2009, que também adotou o algoritmo de Kernel na metodologia.

Decidiu-se pela utilização do algoritmo estimador de densidade de Kernel por esse ser um indicador de fácil uso e interpretação (Cabral \& Souza, 2008).

Notou-se que a distribuição espacial dos focos de calor geradas no mapa de Kernel permitia verificar quais as áreas de maior incidência nos meses mais críticos. O objetivo da análise de Kernel é obter estimativa suavizada da densidade de focos de calor por unidade de área. Essa contagem é ponderada pela distância de cada evento ao ponto de referência dentro de um dado raio, uma propriedade de relevância para a análise da tendência de um processo estocástico espacial (Silva et al., 2009). Para a presente análise definiu-se o raio de influência de 7.500 metros e tamanho de células de $900 \times 900 \mathrm{~m}$. Esses valores foram proposto pelo próprio algoritmo de Kernel, que partiu da amostra estudada. 
Foram criadas faixas de influência (buffers) externas e internas de $10 \mathrm{~km}$ cada, paralelas aos limites das terras indígenas, com o objetivo de se avaliar a influência das terras indígenas na contenção dos incêndios florestais, comparando-se os focos de calor existentes no exterior e no interior dessas áreas protegidas (Figura 2).

Os dados matriciais de densidade de Kernel foram organizados em densidades anuais e acumuladas. Para análise estatística foram elaboradas tabelas no software Excel $^{\circledR}$.

No caso de áreas protegidas é comum a existência de áreas contíguas, formando mosaicos de terras, consequentemente, com a criação de buffers ocorrem casos de sobreposição entre buffers. Assim, para facilitar a contabilização de focos de calor referentes a cada área protegida foram definidas as seguintes regras:

1) nos casos em que houve sobreposição de buffer interno de uma área com externo de outra área, somente o interno foi considerado;

2) nos casos em que houve sobreposição de buffer externo com externo, os dois foram considerados.
Adicionalmente, foram também cruzados os dados de calor com assentamentos, rodovias e mancha urbana para identificar se as zonas com maior densidade podem ser associadas a esses temas.

\section{RESULTADOS E DISCUSSÕES}

Após o tratamento e interpretação dos dados constatou-se um total de 3.395 ocorrências de focos de calor entre janeiro de 2005 e dezembro de 2010 nos municípios estudados.

$\mathrm{Na}$ variação mensal observou-se tendência de aumento das ocorrências de focos de calor a partir de julho, atingindo o máximo em setembro. Nesse mês, as ocorrências corresponderam a 42,6\% (1.526 focos) do total (Figura 3).

A partir de outubro verificou-se tendência de diminuição nas ocorrências de focos de calor, que se manteve em novembro. Em dezembro, o número de focos retornou a valor próximo ao da média do período anterior ao crítico (janeiro a maio). A época crítica

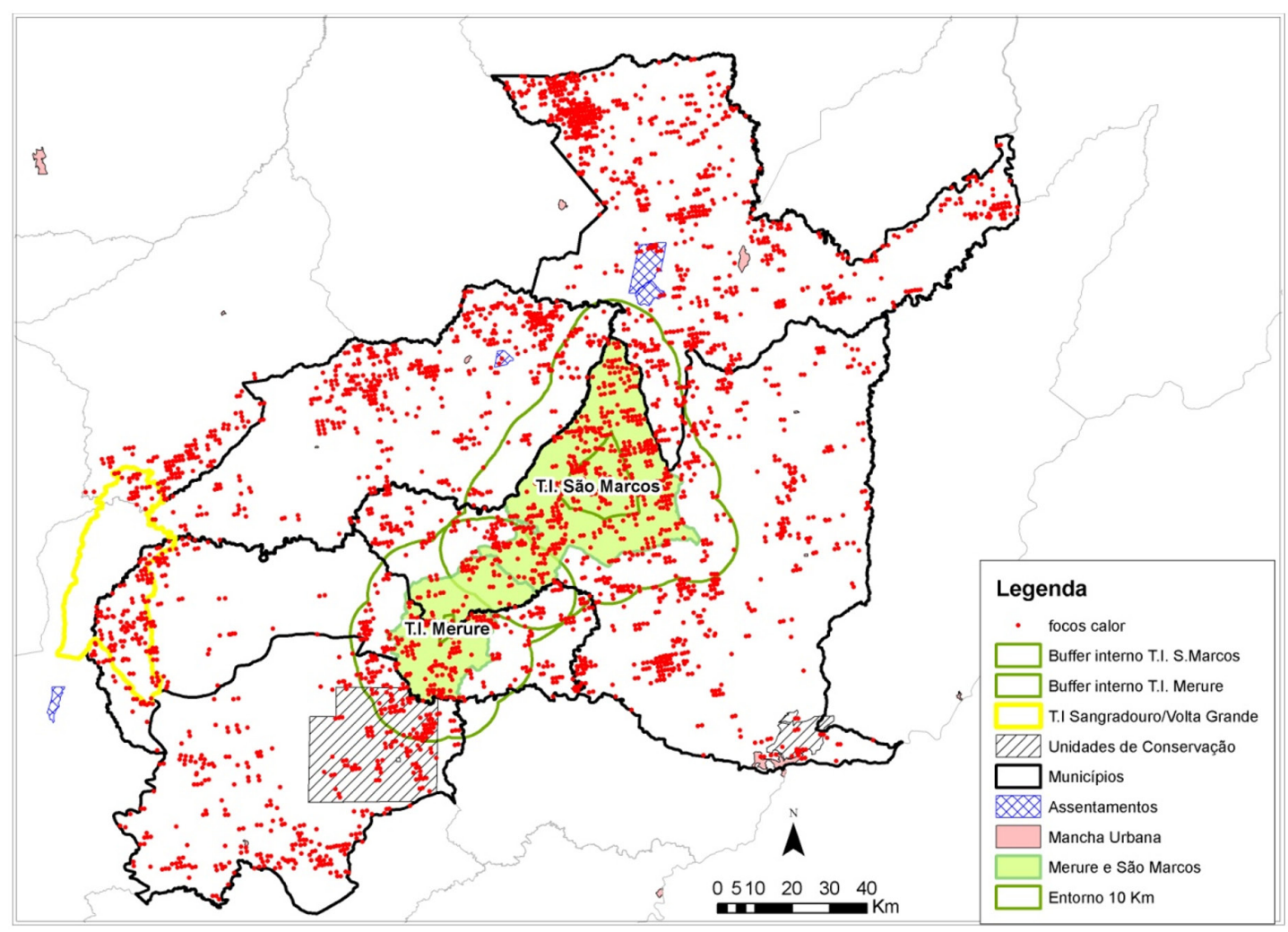

Figura 2. Região de estudo com focos de calor, faixas de influência interna e externa das terras indígenas. Figure 2. Region of study with heat spots, internal and external buffers of the indigenous lands. 


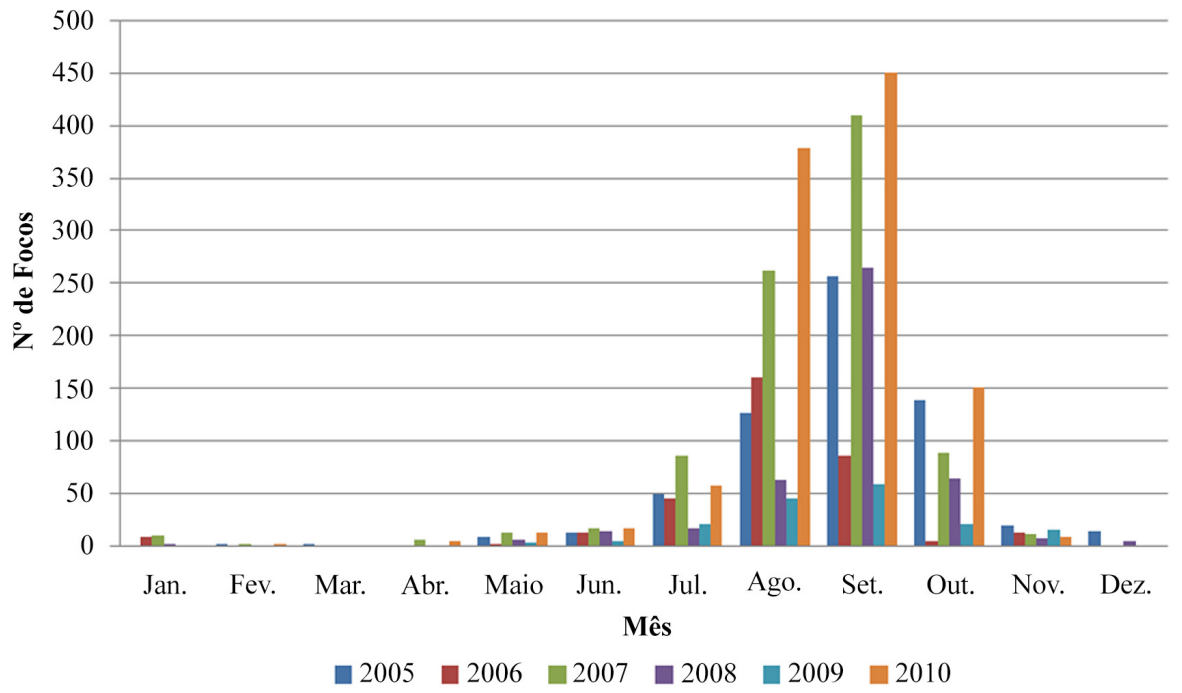

Figura 3. Número de focos totais por ano na região de estudo.

Figure 3. Number of total heat spots in study region per year.

(julho a setembro) se deve à baixa umidade do ar, pela ausência de precipitação e a elevadas temperaturas que são características da região central do Brasil nessa época do ano.

A espacialização dos focos de calor em relação à divisão municipal da região estudada mostrou predominância das ocorrências de focos no município de Barra do Garças, com 1.097 focos de calor, que representaram 32,3\% do total (Tabela 1).

A Figura 4 apresenta as densidades acumuladas de focos de calor na região de estudo entre os anos 2005 e 2010. Essas densidades foram obtidas após a aplicação do algoritmo de densidade de Kernel. As maiores áreas com densidade de focos de calor em maior concentração ocorreram dentro das terras indígenas Merure e São Marcos, porém com características distintas.

Na terra indígena São Marcos observou-se a presença de diversas regiões com densidade de focos média alta, contrastando com a densidade existente nos dez quilômetros na área do entorno, na qual se observou uma concentração menor. Os focos se apresentam distribuídos de forma homogeneamente dentro da terra indígena. Existe apenas uma rodovia estadual, sem pavimento asfáltico, que atravessa a terra indígena na parte sul. Na área externa observou-se predominância de áreas com densidades não relevantes.

Na terra indígena Merure observou-se a presença de densidades relevantes de focos de calor, apresentando-se
Tabela 1. Número total de focos de calor por município. Table 1. Total of heat spots occurred in the municipalities.

\begin{tabular}{lcc}
\multicolumn{1}{c}{ Município } & Número de focos & $\%$ \\
\hline Barra do Garças & 1097 & 32.3 \\
\hline Nova Xavantina & 816 & 24.0 \\
\hline N. São Joaquim & 621 & 18.3 \\
General Carneiro & 458 & 13.5 \\
\hline Tesouro & 403 & 11.9 \\
TOTAL & 3395 & 100 \\
\hline
\end{tabular}

nas classes não relevante, baixa, média baixa e média. Os focos apresentaram-se de forma mais heterogênea, concentrando-se próximo aos limites e às rodovias e estradas existentes em seu interior. Ressaltasse que entre essas vias encontra-se a rodovia BR-070, principal corredor rodoviário entre Mato Grosso, Goiás e Distrito Federal, a qual comporta grande fluxo de veículos de passeio e de carga.

Ao se realizar a sobreposição entre os dados de focos de calor com os de desmatamento notou-se que não há relação entre os dois temas dentro das terras indígenas, já que essas áreas possuem baixa porcentagem de áreas desmatadas.

A maioria dos focos foram detectados nos meses de seca, período do ano em que não ocorrem raios nessas regiões, o que fortalece a hipótese de que esses focos de calor sejam de origem antrópica. 


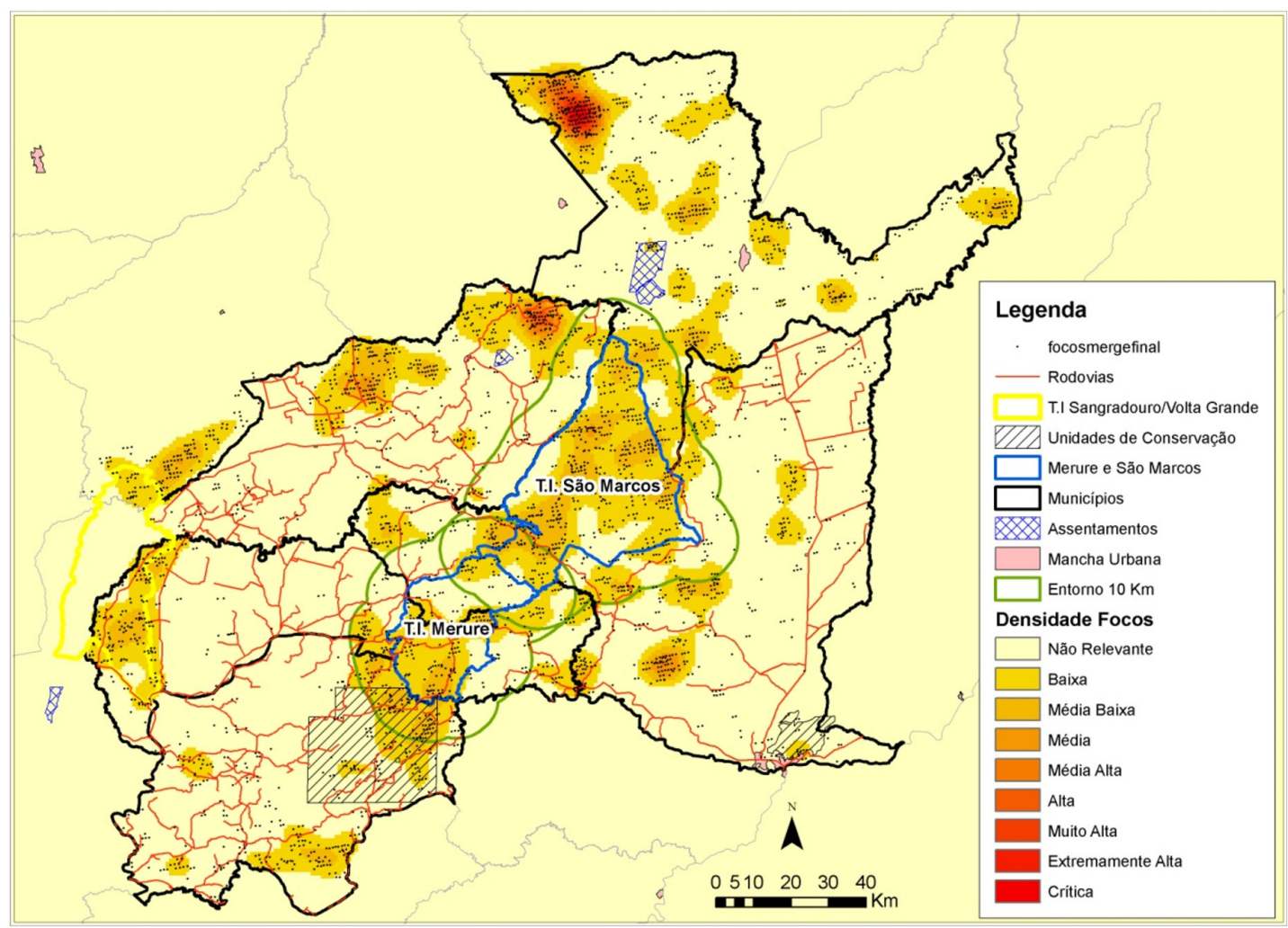

Figura 4. Densidade de focos de calor acumulada entre 2005 e 2010.

Figure 4. Heat spot densities accumulated between 2005 and 2010.

Os focos de calor estudados estavam localizados no buffer interno e externo, ambos no raio de $10 \mathrm{~km}$ dos limites da terra indígena. A observação dos focos de calor indicou que eles se apresentam de forma distinta. Conforme mostrado na Tabela 2, notou-se que as áreas apresentavam influências diferenciadas quanto à contenção dos incêndios florestais. Na terra indígena São Marcos, o número de focos no seu exterior é menor do que em seu interior, o que indicou, a princípio, que essa terra indígena não exerceu influência de área de contenção de incêndios florestais. Já para a Terra Indígena Merure, observou-se o oposto, com menor número de focos em seu interior, o que indicou influência como área de contenção de incêndios.

Na Amazônia Legal, as queimadas geralmente estão associadas à conversão para o uso alternativo do solo. Existe forte relação entre focos de calor e atividades de desmatamento (Aragão et al., 2009). No caso das terras indígenas estudadas, observou-se que não houve essa relação, pois no cruzamento dos dados de desmatamento,
Tabela 2. Focos de calor nas faixas de influência interna e externa de cada terra indígena.

Table 2. Heat spots detected in the internal and external buffers of each indigenous land.

\begin{tabular}{|ccc|}
\hline \multicolumn{3}{|c|}{ Focos de calor nas faixas de influência } \\
\hline Terra indígena & Interno & Externo \\
\hline São Marcos & 376 & 308 \\
\hline Merure & 170 & 239 \\
\hline
\end{tabular}

fornecidos pelo CSR/Ibama e PROBIO/MMA, e focos de calor, constatou-se que as áreas desmatadas nessas terras indígenas foram principalmente anteriores a 2002, conforme Figuras 5 e 6.

Entende-se que mais estudos devem ser conduzidos para continuar avaliando o efeito do fogo em terra indígena localizada na região do Rio das Mortes e propondo estratégias relacionadas ao programa de manejo do fogo (Prada \& Marinho-Filho, 2004). Segundo Melo (2007), ainda são comuns as queimadas realizadas pelos Xavantes em atividades de caça com fogo. 


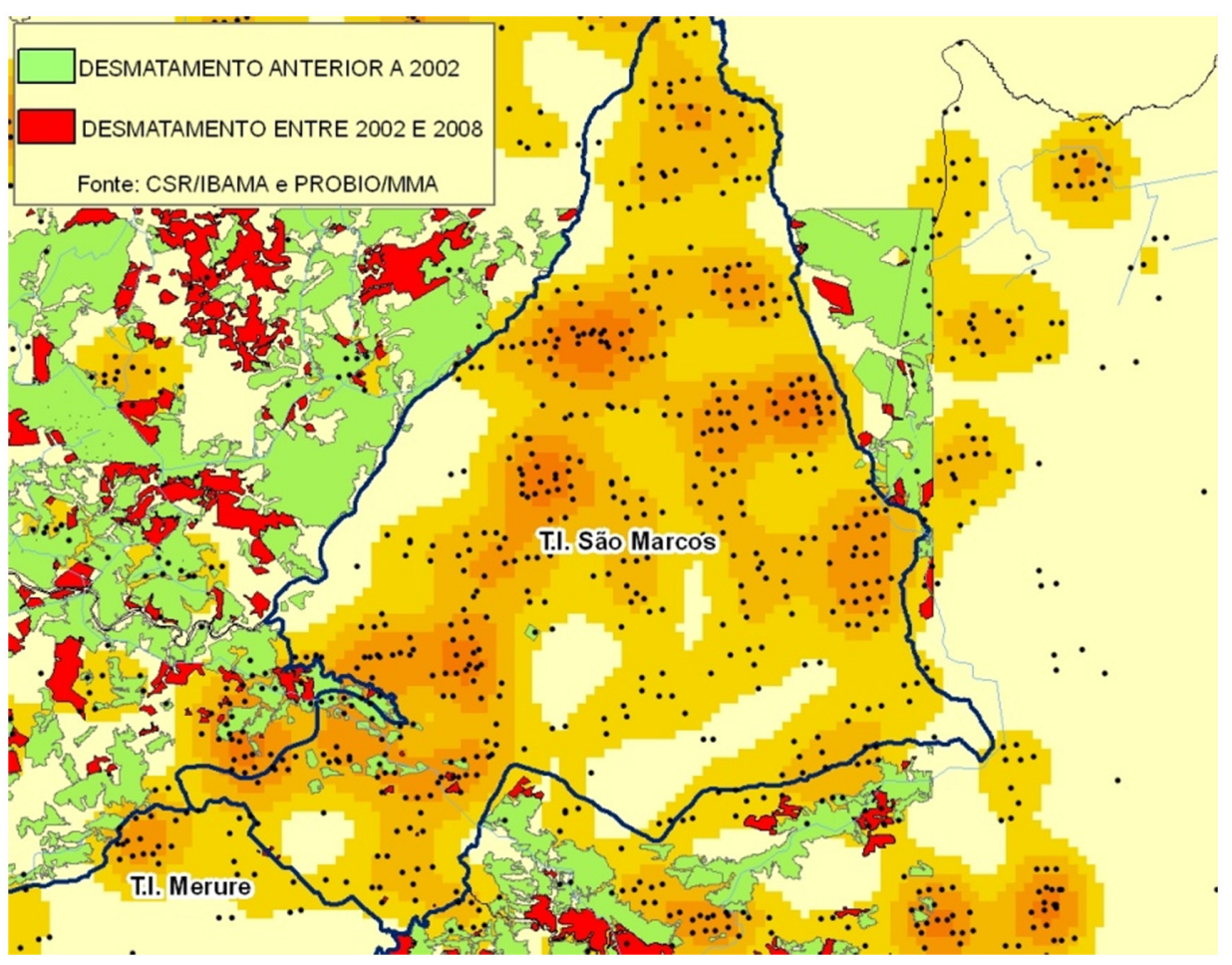

Figura 5. Desmatamentos ocorridos na Terra Indígena São Marcos.

Figure 5. Deforestation occurred in São Marcos indigenous land.

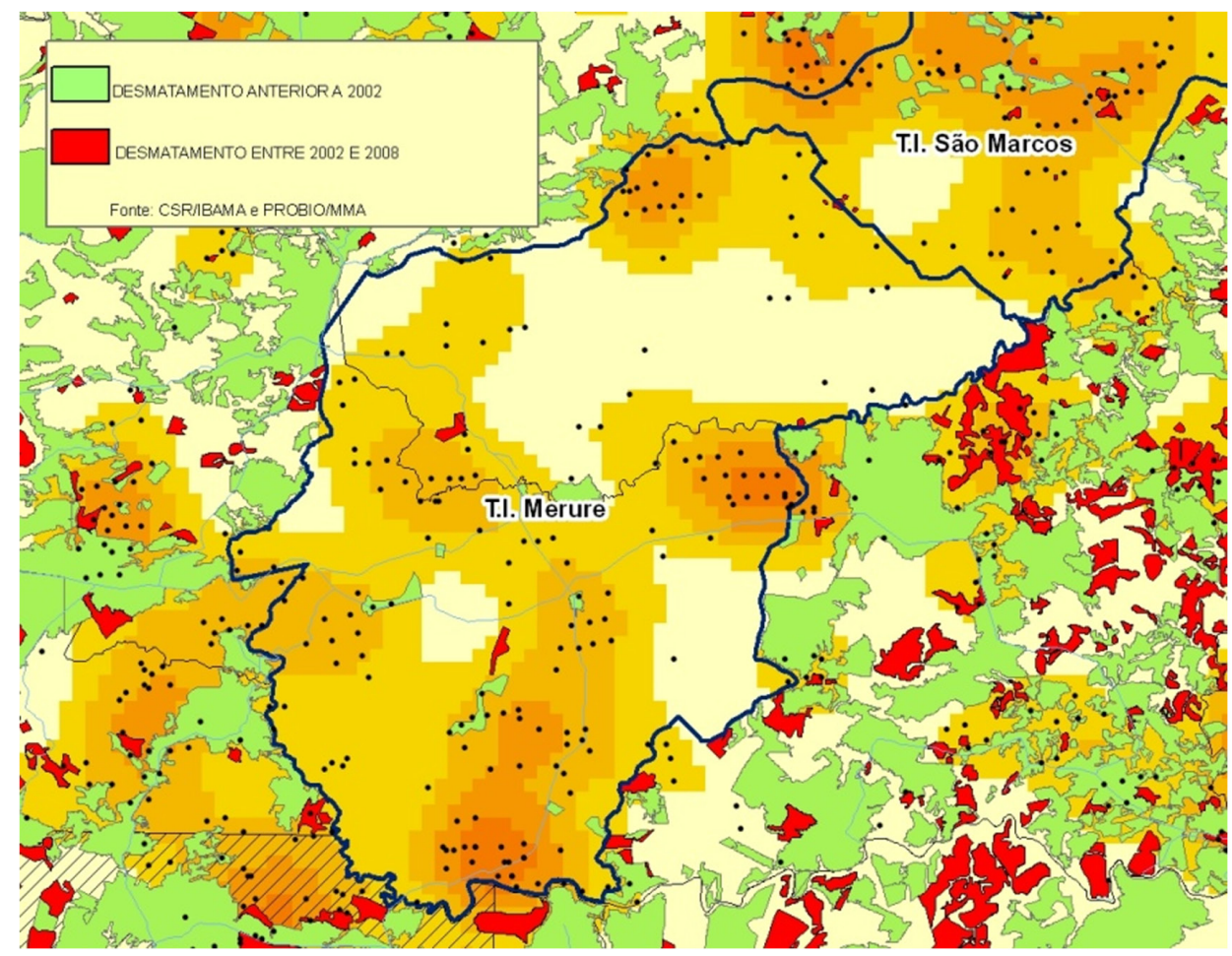

Figura 6. Desmatamentos ocorridos na Terra Indígena Merure.

Figure 6. Deforestation occurred in Merure indigenous land. 


\section{CONCLUSÃO}

A distribuição espacial dos focos de calor nas terras indígenas apresenta padrões diferenciados em relação a outras áreas e entre si.

$\mathrm{Na}$ Terra Indígena Merure, do povo Bororo, os focos de calor foram maiores na área externa. No seu exterior os focos de calor se concentraram em propriedades limítrofes, já no seu interior, a maior intensidade de focos foi em áreas próximas às rodovias, resultando de queimadas provocadas por não indígenas.

Para a Terra Indígena São Marcos, habitada pelo povo Xavante, que tem a cultura do uso do fogo na caça, por meio do círculo do fogo, observou-se maior concentração de focos de calor em seu interior, de forma dispersa no território, nas áreas de vegetação nativa.

\section{STATUS DA SUBMISSÃO}

Recebido: 1 maio, 2013

Aceito: 24 out., 2015

\section{AUTOR(ES) PARA CORRESPONDÊNCIA}

\section{Fabio de Almeida Abreu}

Departamento de Zoneamento Territorial, Ministério do Meio Ambiente, SEPN 505 Norte, Bloco "B", Edifício Marie Prendi Cruz, CEP 70730-542, Brasília, DF, Brasil e-mail: fabio.abreu@mma.gov.br

\section{REFERENNCIAS}

Albues ZS, Rosa R. O uso da terra nas unidades de conservação da Serra Azul- Barra do Garças, MT utilizando imagens Landsat TM e técnicas de geoprocessamento. In: Anais $1^{\circ}$ Simpósio de Geotecnologias no Pantanal [online]; 2006; Campo Grande, Brasil. Campo Grande: Embrapa Informática Agropecuária/INPE; 2006. p. 415-423 [citado 2013 maio 01]. Disponível em: http://mtc-m17.sid.inpe.br/ col/sid.inpe.br/mtcm17@80/2006/12.11.16.56/doc/p53.pdf

Aragão LEOC, Shimabukuro YE, Lima A, Anderson LO, Barbier N, Saatchi S. Utilização de produtos derivados de sensores orbitais para o estudo de queimadas na Amazônia. In: Anais XIV Simpósio Brasileiro de Sensoriamento Remoto; 2009; Natal, Brasil. São José dos Campos: INPE; 2009. p. 919-925.

Cabral APS, Souza WV. Serviço de Atendimento Móvel de Urgência (SAMU): análise da demanda e sua distribuição espacial em uma cidade do Nordeste brasileiro. Revista
Brasileira de Epidemiologia 2008; 11(4): 530-540. http:// dx.doi.org/10.1590/S1415-790X2008000400002.

Castro EA, Kauffman JB. Ecosystem structure in the Brazilian cerrado: a vegetation gradient of aboveground biomass, root mass and consumption by fire. Journal of Tropical Ecology 1998; 14(3): 263-283. http://dx.doi. org/10.1017/S0266467498000212.

Coelho VA. Formação territorial e conflitos entre territorialidades no Brasil Central: o caso Xavante. In: Anais do III Seminário Povos Indígenas e Sustentabilidade: Saberes Locais, Educação e Economia [online]; 2009; Campo Grande, Brasil. Campo Grande: NEPPI; 2009 [citado 2013 maio 01]. Disponível em: http://www. rededesaberes.org/3seminario/anais/textos/Caderno\%20 de\%20Resumos\%20III\%20Semin\%20Sustentabilidade.pdf

Cunha AMC, Lima CA, Dietzsch L. Levantamento de áreas de maior risco de incêndios através de dados NOAA12. Estudo de caso: Reserva Biológica do Guaporé. In: Anais XIII Simpósio Brasileiro de Sensoriamento Remoto [online]; 2007; Florianópolis, Brasil. São José dos Campos: INPE; 2007. p. 4439-4446 [citado 2013 maio 01]. Disponível em: http://bibdigital.sid.inpe.br/rep-/dpi.inpe.br/ sbsr@80/2006/11.15.15.01

Fundação Nacional do Índio - FUNAI. Mapas [online]. Brasília; 2011 [citado 2011 fev. 15]. Disponível em: http:// mapas.funai.gov.br/i3geo/aplicmap/geral.htm?cc530692 a68eb52426b3a69f45cc92a1\#

Gonçalves JS. A prática da queimada no saber tradicional e na concepção científica de risco: estudo sobre o uso do fogo por pequenos produtores do Norte de Minas Gerais. Viçosa: UFV; 2005. 139 p.

Instituto Nacional de Pesquisas Espaciais - INPE. Perguntas freqüentes [online]. São José dos Campos: INPE; 2011 [citado 2013 maio 01]. Disponível em: http://sigma.cptec. inpe.br/queimadas/perguntas.html

Mato Grosso. Secretaria Estadual do Meio Ambiente de Mato Grosso. Coleção monitoramento ambiental 2011 [online]. Cuiabá; 2010 [citado 2013 maio 01]. Disponível em: http://www.sema.mt.gov.br/attachments/article/75/ Focos\%20de\%20Calor_2008\%20e\%202009.pdf

Medeiros MB, Fiedler NC. Incêndios florestais no Parque Nacional da Serra da Canastra: Desafios para a conservação da biodiversidade. Ciência Florestal 2004; 14(2): 157-168.

Melo MM. A confluência entre a ecologia do fogo e o conhecimento Xavante sobre o manejo do fogo no Cerrado [tese]. Brasília: Centro de Densevolvimento Sustentável, Universidade de Brasília; 2007.

Mistry J, Bizerril M. Por que é importante entender as inter-relações entre pessoas, fogo e áreas protegidas? Biodiversidade Brasileira. 2011; 1(2): 40-49. Número Temático: Ecologia e Manejo de Fogo em Áreas Protegidas. Pinto JG, Garavello MEP. Transformação (agri)cultural ou etnossustentabilidade: relato de uma Aldeia Bororo. 
Agroecologia e Desenvolvimento Sustentável [online] 2002; 3(2): 54-60. [citado 2013 maio 01]. Disponível em: http:// www.emater.tche.br/docs/agroeco/revista/ano3_n2/ revista_agroecologia_ano3_num2_parte12_artigo.pdf

Posey D. Manejo da floresta secundária, capoeiras, campos e cerrados. In: Ribeiro B, organizador. Suma etnológica brasileira. Petrópolis: Vozes; 1987. v. 1.

Prada M, Marinho-Filho J. Effects of fire on the abundance of Xenarthrans in Mato Grosso, Brazil. Austral Ecology
2004; 29(5): 568-573. http://dx.doi.org/10.1111/j.14429993.2004.01391.x.

Silva EB Fo, Teles LJS, Santos LA No. Ocorrências de focos de calor no estado de Rondônia em 2007. Sociedade \& Natureza 2009; 21(2): 123-140.

Welch JR, Brondízio ES, Hetrick SS, Coimbra CEA Jr. Indigenous burning as conservation practice: neotropical savanna recovery amid agribusiness deforestation in Central Brazil. PLoS One 2013; 8(12): e81226. http:// dx.doi.org/10.1371/journal.pone.0081226. PMid:24349045. 